\title{
Energy Storage and Stress Analysis of Spiral Spring on Mechanical Elastic Energy Storage Technology
}

\author{
Jing-Qiu Tang \\ Department of Mechanical Engineering \\ North China Electric Power University \\ Baoding, 071003 , China \\ e-mail: tangjingqiu@sina.com \\ Zhang-Qi Wang \\ Department of Mechanical Engineering \\ North China Electric Power University \\ Baoding, 071003 , China
}

\author{
Zeng-Qiang Mi \\ School of Electrical and Electronic Engineering \\ North China Electric Power University \\ Baoding, 071003 , China
}

\author{
Yang $\mathrm{Yu}$ \\ Department of Mechanical Engineering \\ North China Electric Power University \\ Baoding, 071003 , China
}

\begin{abstract}
The energy storage technology plays an important role in the modern power grid. The application of the energy storage technology can improve the stability and controllability of the new energy technologies, and can steady the power grid operation and improve the quality of power supply. In this paper, the principle of energy storage of the mechanical elastic energy storage technology on spiral spring is stated, the method of improving the energy storage density is discussed, and two kinds of section of spiral springs are designed, such as rectangular cross section and special cross section of spiral spring. Aimed to the two kinds of section of spiral springs, the finite element model are medeled, the stress distribution is analysed, and the results of two kinds of spiral spring are compared. With the results of finite element analysis, this paper states the different of two kinds of spiral springs' stress distribution, analyses the area of stress concentration of the special cross section spiral spring, and lays a foundation for further mechanical analysis and structural optimization.
\end{abstract}

Keywords- Mechanical Elastic Energy Storage Technology, Energy storage density, Spiral Spring, Finite Element, Stress

\section{INTRODUCTION}

Due to wind and solar power randomness, intermittent and volatility will cause the change of the power grid voltage, frequency and phase, can affect the stability of modern power grid operation, is not conducive to new energy power generation for power grid. Application of energy storage technology can effectively improve the controllability of the new energy technology, implementation of new energy power generation smooth output, enable new energy power generation stable and reliable to the power grid, and energy storage technology can also be used in modern power grid for the improvement of the power supply quality. Energy storage technology is the technology that the energy is stored with chemical or physical methods, in time of need to release the energy. Energy storage technology at present not unified standard of classification, according to the way of energy conversion, energy storage technology can be divided into physical and chemical, physical form and electromagnetic field can be divided into mechanical energy storage and energy storage, including physical energy storage is also known as mechanical energy storage, including pumping energy storage, compressed air energy storage, flywheel energy storage, such as mechanical energy storage method has a large capacity of energy storage, high efficiency, low cost and no pollution, etc.

Mechanical elastic energy storage technology uses the plane spiral spring as the basic energy storage element. While storing, spiral spring under the influence of working load will produce larger elastic deformation, the mechanical energy or kinetic energy is converted to a spring elastic potential energy. while releasing, the elastic deformation of the spiral spring will disappear, and release the elastic potential energy. The energy will turn into mechanical energy or kinetic energy, or other forms of energy[1-6]. This article expounds the principle of mechanical elastic energy storage technology[7], putts forward the method of improving the energy storage technology of energy storage density, and set up different cross section of the structure of the spiral spring mechanics model and analyzes the relationship between spiral spring section structure and the stress distribution under working load.

\section{SPIRAL SPRING ENERGY STORAGE PRINCIPLE}

\section{A. Spiral spring energy storage process}

Plane spiral spring is the use of thin spring material made into a kind of planar spiral spring, often the spiral spring cross section is rectangular. One end of spiral spring is fixed and the torque is loaded at the other end. The bending elastic deformation will produce on the spiral spring length, so that the spiral spring produce twist in its own plane, storage or release of elastic energy.

Energy storage process of mechanicalelastic energy storage technology can be summed up in spiral spring energy storage process of storage components, the energy storage of spiral spring is the equivalent of the work W 
that the spiral spring rotating the number of work turns $\mathrm{n}$ at work torque T, as (1), $\phi$ is equal to the $2 \pi \times n$.

$$
W=T \times \phi
$$

Spiral spring's torque $\mathrm{T}$ in the working process is following the number of work turns $n$, the change tendency is shown in Fig. 1 .

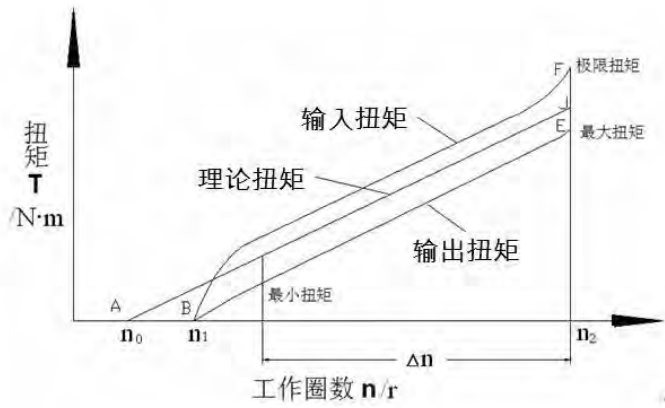

Figure 1. Relationship of torque and work angle

The spring's turns in free state is shown as $\mathrm{n} 0$, the turns released in spring equipment is $n 1$, the turns rolled tightly on shaft is $n 2$. The work turns of spring is $\Delta n=$ $\mathrm{k} 4(\mathrm{n} 2-\mathrm{n} 1)$. Here, $\mathrm{k} 4$ is effective coefficient on the diameter of spring's shaft and the thickness of spiral spring[8].

As shown in Fig .3, the curve of spring work torque is divided into theory torque curve AJ, input torque curve $\mathrm{BF}$ and output torque curve $\mathrm{BE}$. In this paper, only the input torque curve $\mathrm{BF}$ is analyzed. Because of the friction, the left end of input torque curve BF has a curve that means the spring is gradually released. The right end of input torque curve has a curve that means the torque of spring rapidly rise after the spring is tightened round the shaft. In fact, during the process of energy storage, only the torque is used while the spring deforms all over the spring. Shown in Fig .3, this stage of the curve is the $\Delta \mathrm{n}$. This time, the curve tends to straight line. In the $\Delta \mathrm{n}$ stage, the curve of work torque is approximately linear[9].

The Work torque of spiral spring can be calculated as formula (2) and formula (3). Elastic modulus $\mathrm{E}$ and moment of inertia I are proportional to work torque. The limit torque $T_{\max }$ of spiral spring is checked by the tensile strength limit value $\left[\sigma_{b}\right]$ of spring's material. $Z_{m}$ is the section coefficient of bending.

\section{B. Spiral spring force analysis}

Shown in Fig .2, one end of spring is fixed, the fixed point is $\mathrm{A}$, the other end is fixed at point $\mathrm{O}$. The distance from point $\mathrm{A}$ to point $\mathrm{O}$ is $\mathrm{r}$. When the torque is loaded at point $\mathrm{O}$, the loads at point $\mathrm{A}$ include torque $\mathrm{T}_{1}$, tangential force $\mathrm{P}_{\mathrm{t}}$ and Radial force $\mathrm{P}_{\mathrm{r}}[10]$.

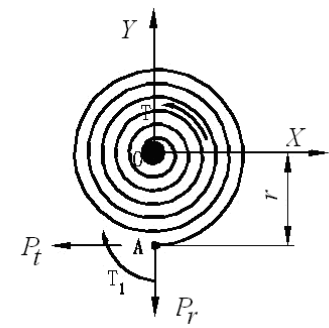

Figure 2. Force analysis of flat spiral spring
The Work torque of spiral spring can be calculated as (2) (3). Elastic modulus E and moment of inertia I are proportional to work torque. The limit torque $T_{\max }$ of spiral spring is checked by the tensile strength limit value $\left[\sigma_{b}\right]$ of spring's material. $Z_{m}$ is the section coefficient of bending[11].

$$
\begin{aligned}
& T=\frac{E I}{l} \varphi=\frac{2 \pi n E I}{l} \\
& \frac{T_{\max }}{Z_{m}} \leq\left[\sigma_{b}\right]
\end{aligned}
$$

The commonly cross section of spiral spring is rectangular. The moment of inertia $\mathrm{I}$ and the section coefficient of bending $Z_{\mathrm{m}}$ of spring can be calculated as as (4) (5) (6). In formulas, b is the width of cross section, and $h$ is the thickness of cross section.

$$
\begin{gathered}
I=\frac{b h^{3}}{12} \\
Z_{m}=\frac{I}{y_{\text {max }}}=\frac{b h^{3} / 12}{h / 2}=\frac{b h^{2}}{6} \\
T_{\max } \leq \sigma_{b} \times Z_{m}=\sigma_{b} \times \frac{I}{y_{\text {max }}}=\sigma_{b} \times \frac{b h^{2}}{6}
\end{gathered}
$$

The maximum torque and minimum work torque of spiral spring can be calculated as (7) (8), $K_{3}$ is fixed coefficient.

$$
\begin{aligned}
& T_{2}=K_{3} \times T_{\max } \\
& T_{1}=0.5 \times T_{2}
\end{aligned}
$$

\section{Method of enhancing energy storage density}

According to (4)(5)(6)(7)(8), conclusion can be get.

1) At the neutral axis of spiral spring section, the bending moment is equal to zero, namely the spiral spring work torque doesn't work.

2) The material near the neutral axis of Spiral spring section little impact coefficient of moment of inertia and bending section.

According to the discussion above, the method of improving spiral spring energy storage density is reducing the material near the neutral axis of rectangular section spiral spring, establishing special section spiral spring. Two kinds of spiral spring's cross-sections is shown in Fig.3.
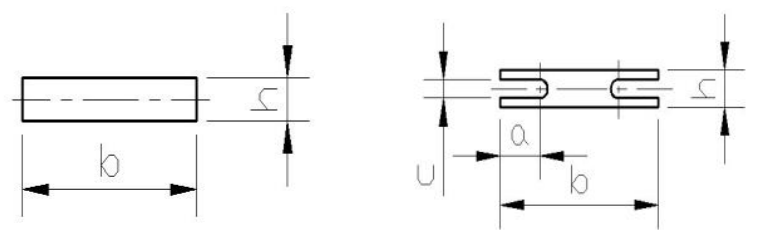

(a) rectangular cross section (b) special craoss section Figure 3. Cross sections of spiral spring 


\section{MECHANICS ANALYSIS OF SPIRAL SPRING}

\section{A. Finite element model}

According to Fig .3, the rectangular cross-section of spiral spring and finite element model of special section spiral spring are established. In order to simplify the calculation, a certain length of spiral spring can be intercepted for mechanics analysis. while the spiral spring's torque is maximum torque $T_{2}$, the analysis can be done for the stress distribution characteristics of spiral spring.

The arc length $l$ of spiral spring intercepted is $80 \mathrm{~mm}$, the arc radius $\mathrm{R}$ is $80 \mathrm{~mm}$, the material of spring is $55 \mathrm{CrMnA}$, the modulus is of elasticity other parameters is shown as Table I.

TABLE I. MATERIAL PROPERTIES OF SPIRAL SPRING

\begin{tabular}{|c|c|c|}
\hline Spring type & $\begin{array}{c}\text { Rectangular } \\
\text { spiral spring }\end{array}$ & $\begin{array}{c}\text { Special spiral } \\
\text { spring }\end{array}$ \\
\hline $\begin{array}{c}\text { Modulus of } \\
\text { elasticity E/Gpa }\end{array}$ & 197 & 197 \\
\hline $\begin{array}{c}\text { Tensile strength } \\
\sigma_{b} / \text { Mpa }\end{array}$ & 1653 & 1653 \\
\hline Material & $55 \mathrm{CrMnA}$ & $55 \mathrm{CrMnA}$ \\
\hline$T_{2}(\mathrm{~N} \cdot \mathrm{m})$ & 9.918 & 9.149 \\
\hline$T_{1}(\mathrm{~N} \cdot \mathrm{m})$ & 4.959 & 4.574 \\
\hline $\mathrm{a}(\mathrm{mm})$ & - & 2.5 \\
\hline $\mathrm{b}(\mathrm{mm})$ & 10 & 10 \\
\hline $\mathrm{c}(\mathrm{mm})$ & - & 2 \\
\hline $\mathrm{h}(\mathrm{mm})$ & 2 & 1 \\
\hline $\mathrm{Asthe} \mathrm{Tabl}$ & $5 \mathrm{n}$ & \\
\hline
\end{tabular}

As the Table I shown, the models of the cross section of spiral spring can be set up, and imported into the ANSYS software system. With entity modeling and the hexahedral element meshing, two kind of cross-sections of spiral spring finite element model can be established[12, 13].

\section{B. $\quad$ Spiral spring stress analysis}

Because the working process of the plane spiral spring is in Elastic deformation range, the analysis can be as a general linear problem analysis, no special definition of nonlinear materials.

Loading bending moment $T_{2}$ on two end face of the finite element model, two kinds of spiral spring's deformations and Stress diagrams can be generated, with the proportion of 1:1. Using Von Mises Stress (Miese equivalent Stress) for stress analysis, the result is shown in Fig.4.

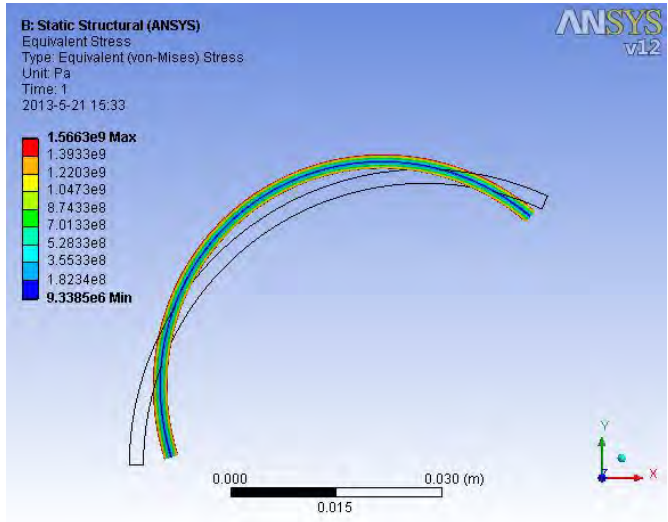

(a) stress of rectangular cross section spring

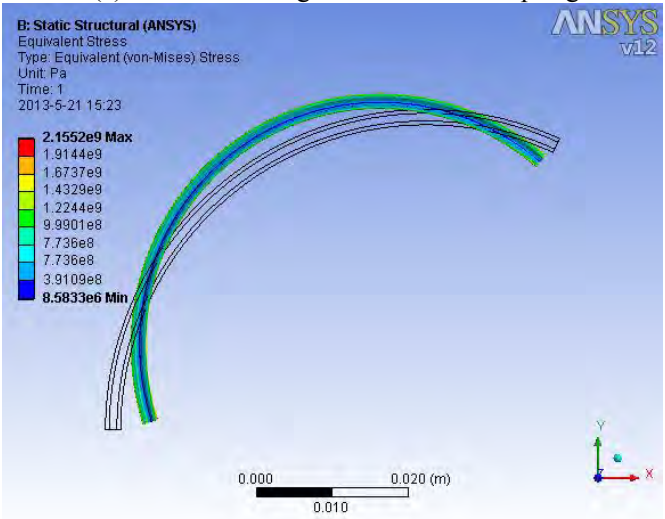

(b) stress of special cross section spring

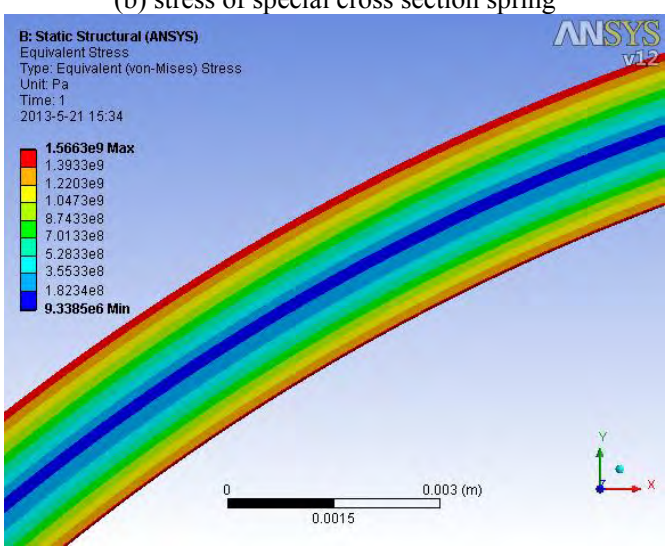

(c) local stress of rectangular cross section spring

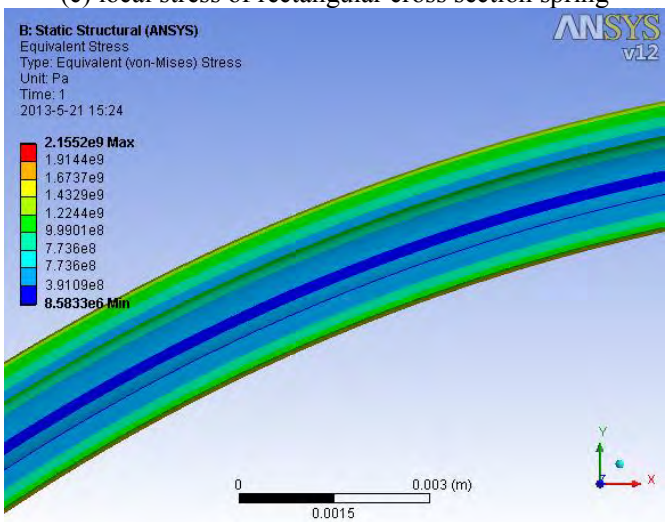

(d) local stress of special cross section spring 


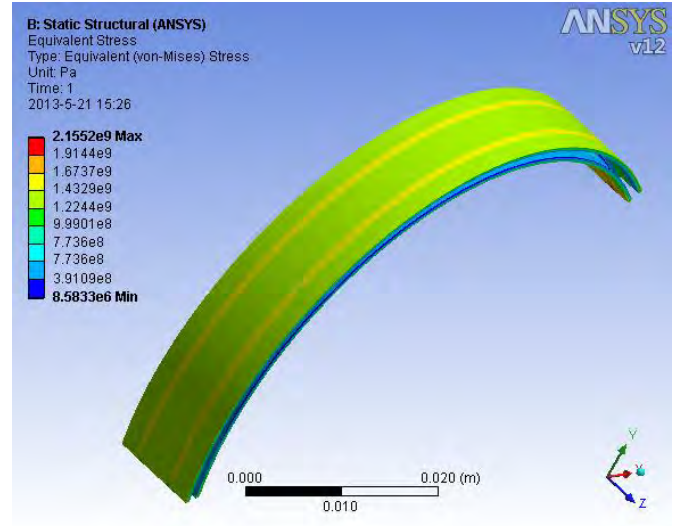

(e) surface stress of special cross section spring

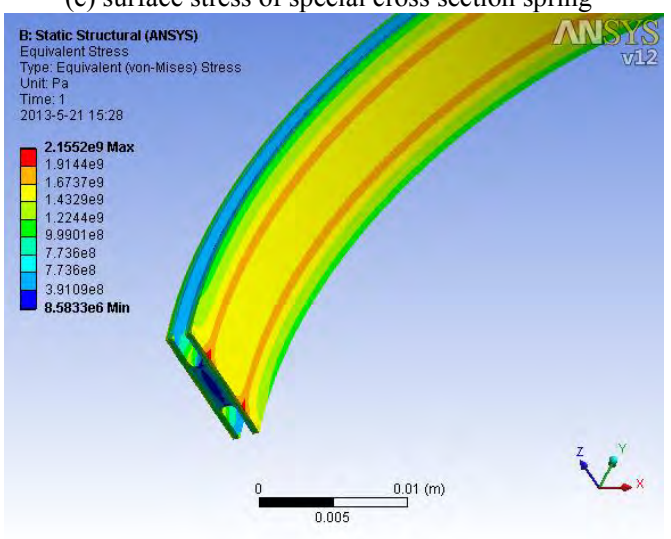

(f) local stress of special cross section spring

Figure 4. Results of stress anslysis

\section{Results analysis}

$\mathrm{A}$ and $\mathrm{b}$ figure in the Fig .5 show the two kinds of spiral spring's stress distribution with their respective maximum work torque, the wireframe represents the shape of the segment of spiral spring without the bending moment.

$\mathrm{C}$ and $\mathrm{d}$ figure in the Fig .5 show the two kinds of spiral spring's stress distribution of local amplification. According to $\mathrm{c}$ and $\mathrm{d}$ figure, it can be clearly seen that under the effect of maximum torque, the stress of spiral spring is layered, and near the neutral axis of cross section, stress is minimum. Away from the neutral axis, stress increases gradually. At a distance from the neutral axis, stess is the most peak.

$\mathrm{E}$ and $\mathrm{f}$ figure in the Fig .5 show the stress distribution on special cross-section springs surface with maximum work torque. Can know from the table, the special sping's stress on the surface is not a constant value, which on the middle and two wings of the spiral sping is relatively small. The stress is largest on the area where the spiral spring's plane of two flanks hollow part and the spiral sping's hemicycle are tangent.

\section{CONCLUSION}

This paper expounds the principle of mechanical elastic energy storage technology and the method of enhancing the energy storage energy storage density, and sets up different cross section of the structure of the spiral spring mechanics model, analyzes the stress distribution of spiral spring with the maximum work torque, and the influence of spiral spring section on the stress distribution, the stress distribution of special cross-section spiral spring, points out the area of stress concentration of different section of spiral springs. Which provide the calculation basis for the precision mechanical analysis, the structure optimization and the optimization of energy storage density of spiral spring.

\section{ACKNOWLEDGMENT}

This work is supported by Basic Research Fund of National Higher Education (Grant No. 916041101), New Energy Power System State Key Laboratory Independent Research Subject(Grant No. 201209), Higher School Specialized Research Fund For The Doctoral Program(priority development field) (Grant No. 20120036130001)

\section{REFERENCES}

[1] WEI Zengfu, ZHENG Jin. Energy storage techniques applied in smart grid[J]. Guangdong Electric Power, 2010, 23(11): 22-27.

[2] JIA Hongxin, Zhang Yu, WANG Yufei, et al. Energy storage for wind energy applications[J]. Renewable Energy Resources, 2009, 27(6): $10-15$

[3] GEORGESCU M, BAROTE L, MARINESCU C, et, Smart electrical energy storage system for small power wind turbines[C]//12th International Conference on Optimization of Electrical and Electronic Equipment, Piscataway: IEEE, 2010:1192-1197.

[4] ZHANG Wenliang, QIU Ming, LAI Xiaokang. Application of energy storage technologies in power grids[J]. Power System Technology, 2008, 32(7): 1-9

[5] CHENG Shijie, LI Gang, SUN Haishun, et al. Application and Prospect of Energy Storage in Electrical Engineering[J]. Power System and Clean Energy, 2009, 25(2): 1-8.

[6] JIN Jianding, Development opportunities of energy storage componet and its equipment for new energy[J].Electronics Process Technology, 2009, 30(5):258-260.

[7] Duan Wei, Feng Hengchang Wang Zhangqi. Finite element analysis of flat spiral spring in elastic energy storage device[J]. Chinese Journal of Construction Machinery, 2011,9(4): 493-498.

[8] JIANG Ying, ZHANG Yinghui, WAN Guixiang, et al. Calculation of flat spiral spring design[M]. Beijing: China Machine Press, 1994.

[9] WANG Zengxiang, WEI Xianying, LIU Xiang, et al. Spring design manual[M]. Shanghai: Shanghai Science and Technology Literature Press, 1986

[10] ZHANG Yinghui. Spring[M]. Beijing: China Machine Press, 1982: 310-317

[11] LIU Hongwen. Mechanics of materials : I[M]. Beijing: Higher Education Press, 1992.

[12] BOYI Workshop. ANSYS9.0 classic products basic tutorials and example explanation[M] . Beijing: China WaterPower Press :

[13] LIU Guo-qing, YANG Qing-dong, ANSYS Engineering Application Tutorial:Mechanics[M]. Beijing: China Railway Press, 2003 